J. Egypt. Soc. Parasitol. (JESP), 51(1), 2021: 23 - 28

(Online: 2090-2549)

\title{
ASSESSMENT OF THE EFFECT OF ALLIUM SATIVUM (GARLIC) AND CURCUMA LONGA (CURCUMIN) IN COMBINATION WITH DRUGS ON CULTURED TRICHOMONAS VAGINALIS
}

\author{
By \\ AHMED K. DYAB ${ }^{1 *}$, HANY A. FAROUK ${ }^{2}$, MOHAMMED F. MOHAMMED ${ }^{3}$ \\ AND YASSER M. MOHAMED ${ }^{1}$
}

Department of Medical Parasitology, Faculty of Medicine, Assiut University, 71515

Assiut ${ }^{1}$, Department of Gynecology and Obstetrics ${ }^{2}$, and, Department of Medical

Parasitology ${ }^{3}$, Faculty of Medicine Aswan University, Egypt

( ${ }^{*}$ Correspondence: Ahmed2015@aun.edu.eg, ORCID:0000-0002-4021-7904)

Abstract

Trichomoniasis is an infectious disease caused by Trichomonas vaginalis. It inflicts severe complications to human genitourinary system. The devastating negative effects and resistance emerged to known medication impose the search for effective and safer alternatives. This study evaluated the effect of curcumin and garlic as well as combination between their effective doses with Metronidazole ${ }^{\circledR} \&$ Tinidazole $^{\mathbb{R}}$. So, vaginal swabs were obtained from the symptomatic patients, and cultured on modified Diamond's medium. Assessment of the herbs various concentrations at different follow-up periods was done by counting dead T. vaginalis trophozoites by using hemocytometer and trypan blue staining. The results showed that curcumin $400 \mathrm{mg} / \mathrm{ml}$ gave a promising anti-Trichomonas especially when combined with garlic $90 \mathrm{mg} / \mathrm{ml}$ that showed a high synergistic effect.

Keywords: Curcumin, Garlic, Trichomonas vaginalis, Culture, Metronidazole, Tinidazole

\section{Introduction}

Trichomoniasis is a sexually transmitted worldwide disease caused by protozoan $T$. vaginalis (Poole and McClellan, 2013). It was considered as a re-emerging infectious disease (Setzer et al, 2017). It mainly affects male \& female urogenital tract particularly childbearing ones (Paz-Bailey et al, 2010). Trichomoniasis prevalence between 2012 \& 2016 was 110.4million cases (Rowley et $a l, 2019)$. Clinically, it varies between asymptomatic and carriers, to symptomatic; cervicitis, urethritis and serious pelvic inflammations (Poole and Mc Clellan, 2013), to infertility, cervical cancer and HIV (Tsevat $e t$ $a l, 2017)$. Trichomoniasis in man causes urethritis, epididymitis, prostatitis and infertility or prostatic cancer (Sutcliffe et al, 2012). There were many diagnostic methods, as staining, immunochromatography and nucleic acid amplification (Chalamilla et al, 2006), and serology as ELISA (Sharma et al, 1991) or PCR (Walsh et al, 1991). But, Diamond's medium (modified) gave a more prolific growth over a shorter time as the golden standard for $T$. vaginais diagnosis and research studies (Gelbart et al, 1990).
Trichomoniasis ongoing drugs are metronidazole (MTZ) and tinidazole. Metronidazole is an antibiotic member of 5-nitroimidazole family (Muzny and Schwebke, 2013). It has many side effects (Ali and Nozaki, 2007) particularly when higher doses were indicated in steadily increased resistant cases (Howe and Kissinger, 2017). MTZ causes nausea, dizziness, hypersensitivity, dermatitis (Schwebke and Barrientes, 2006), and with teratogenic \& carcinogenic effects on fetus (Calzada et al, 2007). But, no alternative safe therapy to overcome these serious side effects or treat the resistant trichomoniasis cases (Unemo et al, 2017). This emphasized the urgent need for safe effective treatment of medicinal plants or herbs origin (Abdel Hady et al, 2008).

Allium sativum (Garlic) is a popular vegetable which is used as a spice and food additive (Singh et al, 2009) and in modern medicine (Martins et al, 2016). Thiosulfinates, sulphur-containing amino acids, and allicin are responsible for the therapeutic benefit of garlic (Hornickova et al, 2010).

Sulphur compounds have antimicrobial, anticancer, antioxidant, anti-inflammatory, 
cardio-protective, antidiabetic and immunomodulatory activities (Lanzotti et al, 2014), and the produce glutathione has antioxidant activity (Banerjee et al, 2003). Garlic active the immune cells via allicin bioactive properties (Alorainy, 2011), anti-protozoal effect (Ayrle et al, 2016) and anti-cryptosporidiosis (Abouel-Nour et al, 2016). Nigella sativa ( $N$. sativa) is an ancient annual plant, with therapeutic activities against Trichomonas vaginalis (Al-Am-mash, 2017), hepatitis C virus, and Helicobacter pylori (Tavakkoli et al, 2017).

Curcumin is a polyphenol extract from the common spice turmeric (Curcuma longa), a rhizomatous perennial plant use in Indian Ayurvedic Medicine for thousands of years (Sharma et al, 2005). It is also used for food coloring (Buescher and Yang, 2000) and studied for biological effects. An impressive array of potent pharmacological effects were reported; as inhibitory effects on Giardia lamblia (Perez-Arriaga et al, 2006), Eimeria tenella sporozoites (Khalafalla et al, 2011), Plasmodium spp. (Mimche et al, 2011), Cryptosporidium parvum (Shahiduzzaman et al, 2009), Schistosoma mansoni (Allam, 2009), Leishmania amazonensis, L. mexicana \& Trypanosoma brucei (Changtam et al, 2010), and HIV (Barthelemy et al, 1998), Also, it is anti-oxidant (Wei et al, 2003) anti-inflammatory (Chainani-Wu, 2003), anti-carcinogenic (Devasena et al, 2003), immuno-modulatory (Yadav et al, 2005), and supported curcumin and its derivatives as broad-spectrum antiviral agents (Jennings and Parks, 2020) Also, it has protective effect on $\beta$-pancreatic cells (Srivivasan et al, 2003). So, curcumin fulfils the basic requirements of a potential effective \& safe drug, cheap, available and well tolerated.

This study aimed to evaluate the anti-Trichomonas effect of curcumin \& garlic alone or combined versus metronidazole and tinidazole.

\section{Material and Methods}

This study was done in the Research Laboratory, Department of Medical Parasit- ology, Faculty of Medicine, Aswan University from December 2019 to November 2020.

Culture: Vaginal swabs were taken from 30 females with suspected trichomoniasis. Wet mounted samples were immediately examined (Patil et al, 2012) or preserved in amines transport medium for $24-48 \mathrm{hrs}$. From 30 positive samples, parasites were grown on pH6.2 modified Diamond's medium (Diamond, 1957) and Broth medium (Rayner, 1968), supplemented with fetal bovine serum and mixture of penicillin and streptomycin at $37^{\circ} \mathrm{C}$. T. vaginalis maintenance was subculture (Diamond and Bartgis, 1962).

Drugs and herbs: MTZ (250mg) tablets were crushed, dissolved in distilled water, and diluted in culture medium $(100 \mathrm{mg} / \mathrm{ml})$. Garlic or Tomex $(90 \mathrm{mg} / \mathrm{ml})$ were prepared. Curcumin was dissolved in polyethylene glycol (PEG) to have 10\% stock solution that was diluted to gain an appropriate working solution of $1.600 \mathrm{mg}$ curcumin $/ \mathrm{ml}$. This solution was diluted into wells as $800 \& 400 \mathrm{mg} /$ $\mathrm{ml}$, respectively (Ibrahim, 2013).

Experimental design: $T$. vaginalis trophozoites were cultured on Broth and modified Diamond's media. Cultures treated with different metronidazole, tinidazole, curcumin and garlic. Different MTZ doses were tested to highest effective dose or as a positive control.

$T$. vaginalis trophozoites were incubated $\left(3 \times 10^{4}\right.$ cells/tube $)$ with each herb as duplicate for $24,48 \& 72 \mathrm{hrs}$. Both MTZ treated culture and control cultures (parasite only), were procedure for extracts. Combined groups included MTZ and the highest effective herbal dose.

Effect of different agents' on $T$. vaginalis was done by: a- Inverted microscopic examination after $24 \mathrm{hrs}, 48 \mathrm{hrs} \& 72 \mathrm{hrs}$. b- Hemocytometer and trypan blue stained to count the dead trophozoites after $24 \mathrm{hrs}, 48 \mathrm{hrs} \&$ 72hrs (Arbabi et al, 2016).

Statistical analysis: Data were computerized and statistically analyzed using SPSS program (Statistical Package for Social Science) version 25.0 and the ANOVA. 
Ethical approval: The study was approved by the Ethics Committee and Review Board, Faculty of Medicine, Aswan University, and signed consents were taken from patients.

\section{Results}

Dead T. vaginalis trophozoites on modified Diamond's medium were less than Broth medium with significant difference at follow up. Combination between curcumin 400 $\mathrm{mg} / \mathrm{ml}$. \& tomex $90 \mathrm{mg} / \mathrm{ml}$. gave the highest mean of trophozoites death at different periods with significant $(\mathrm{p}<0.001)$. Curcumin $400 \mathrm{mg} / \mathrm{ml}$. \& MTZ100 mg/ml. gave a good

Table 1: Comparison between modified Diamond \& Broth medium as to dead T. vaginalis trophozoites.

\begin{tabular}{|l|c|c|c|}
\hline Culture & After 24hrs & After 48hrs & After 72hrs \\
\hline Modified Diamond & $15 \pm 5$ & $18 \pm 3$ & $35 \pm 2$ \\
\hline Broth medium & $100 \pm 4$ & $220 \pm 7$ & $270 \pm 9$ \\
\hline
\end{tabular}

Modified Diamond's medium gave better survival of T. vaginalis trophozoites.

Table 2: Effect of metronidazole, tinidazole, tomex \& curcumin on mean dead T. vaginalis trophozoites at different periods.

\begin{tabular}{|l|c|c|c|c|}
\hline Agent & After 24hrs & After 48hrs & After 72hrs & P value \\
\hline Modified Diamond's medium (negative control) & $15 \pm 5$ & $18 \pm 3$ & $35 \pm 2$ & 0.01 \\
\hline Metronidazole100mg/ml (positive control) & $6 \pm 2$ & $24 \pm 8$ & $70 \pm 20$ & 0.001 \\
\hline Tinidazole $100 \mathrm{mg} / \mathrm{ml}$ & $10 \pm 4$ & $30 \pm 7$ & $100 \pm 20$ & 0.001 \\
\hline Tomex $90 \mathrm{mg} / \mathrm{ml}$ & $15 \pm 2$ & $40 \pm 4$ & $50 \pm 9$ & 0.001 \\
\hline Curcumin $400 \mathrm{mg} / \mathrm{ml}$ & $18 \pm 2$ & $45 \pm 3$ & $120 \pm 8$ & 0.001 \\
\hline P value & $<0.001$ & $<0.001$ & $<0.001$ & \\
\hline
\end{tabular}

Curcumin $400 \mathrm{mg} / \mathrm{ml}$ gave highest death after $72 \mathrm{hrs}$ with significant $(\mathrm{p}<0.001)$.

Table 3: Combined effect with metronidazole, tinidazole, tomex \& curcumin on trophozoites death at different periods.

\begin{tabular}{|l|c|c|c|c|}
\hline Agent & After 24hrs & After 48hrs & After 72hrs & P value \\
\hline Modified Diamond's medium (negative control) & $15 \pm 5$ & $18 \pm 3$ & $35 \pm 2$ & 0.01 \\
\hline Metronidazole100mg/ml(positive control) & $6 \pm 2$ & $24 \pm 8$ & $70 \pm 20$ & 0.001 \\
\hline Metronidazole100mg \& tomex 90 mg/ml & $40 \pm 5$ & $60 \pm 9$ & $110 \pm 15$ & 0.001 \\
\hline Tinidazole 100mg/ml \& tomex 90mg/ml & $60 \pm 4$ & $90 \pm 7$ & $120 \pm 11$ & 0.001 \\
\hline Metronidazole100mg/ml \& curcumin400mg/ml & $30 \pm 3$ & $50 \pm 6$ & $70 \pm 8$ & 0.001 \\
\hline Tinidazole 100mg/ml \& curcumin 400mg/ml & $60 \pm 9$ & $95 \pm 8$ & $130 \pm 5$ & 0.001 \\
\hline Tomex 90mg/ml \& curcumin 400mg/ml & $70 \pm 3$ & $100 \pm 3$ & $135 \pm 4$ & 0.001 \\
\hline P value & $<0.001$ & $<0.001$ & $<0.001$ & \\
\hline
\end{tabular}

\section{Discussion}

The present study investigated the efficacy of different concentrations of commercially available garlic tablet (Tomex) and curcu$\min 400 \mathrm{mg} / \mathrm{ml}$, their combination between their highest effective doses with metronidazole and Tinidazole against $T$. vaginalis infection at $24,48,72 \mathrm{hrs}$ follow up periods.

In the present study, the mean number of dead trophozoites on modified Diamond's medium was less than Broth medium with significant difference at all follow up periods. This agreed with Gelbart et al. (1990) who recommended modified Diamond's medium as the medium of choice for T. vaginalis. gave the highest dead $T$. vaginalis trophozo-
In the present study, Tomex $90 \mathrm{mg} / \mathrm{ml}$ caused the highest dead trophozoites after $72 \mathrm{hrs}$ $(50.00 \pm 9.00)$, but MTZ $100 \mathrm{mg} / \mathrm{ml}$ gave higher effect $(70.67 \pm 20.50)$. This agreed with both Ahmed (2010), and Ibrahim (2013) reported that garlic was as efficient as metronidazole to prevent trophozoites multiplication and motility. Alyasari et al. (2018) reported that aqueous garlic extract completely inhibited $T$. vaginalis growth, viability and motility. No doubt, allicin production of tomex (Ross et al, 2001) disrupted the normal Trichomonas physiological functions (Masamha et al, 2010).

In the present study, curcumin $400 \mathrm{mg} / \mathrm{ml}$ ites $(120.00 \pm 8.01)$ after $72 \mathrm{hrs}$ compared to 
was used positive control. This agreed with Tonkal (2009) who found that curcumin 400 $\mathrm{mg} / \mathrm{ml}$ markedly inhibited $T$. vaginalis trophozoites' growth. Mahmoud et al. (2011) and Al-Ammash (2017) reported that curcumin $400 \mathrm{mg} / \mathrm{ml}$ had an in vitro anti-Trichomanas effect. Curcumin proved to have an anti-adhesion effect for $T$. vaginalis to human epithelial cells (Shaaban et al, 2011).

In the present study, metronidazole $100 \mathrm{mg} /$ $\mathrm{ml}$ alone or combined with the most effective Tomex concentration $(90 \mathrm{mg} / \mathrm{ml})$ and curcumin $(400 \mathrm{mg} / \mathrm{ml})$ on $T$. vaginalis trophozoites gave the best anti-trichomonas effect $(70 \pm 8.00)$ as a new treatment era.

No doubt, the herbs showed a synergistic effect when combined with drugs by modifying the intestinal and hepatic metabolizing enzymes (Boullata, 2005). Wachter et al. (2014) in Austria found that curcumin proved to be a promising candidate for trichomonosis topical treatment. Mady et al. (2016) in Egypt showed that combination between Daraprim $^{\circledR}$ and NSO against murine toxoplasmosis was better than the herb alone. Nassef et al. (2018) in Egypt combined between cisplatin, a cytotoxic drug, and NSO for Trypanosome evansi treatment. Mallo et al. (2020) in Spain demonstrated the potential usefulness of curcumin as an anti-parasitic and anti-inflammatory treatment for trichomoniasis, and added that could be used to control the disease and mitigate the associated immunopathogenic effects.

In the present study, significantly higher metronidazole was needed to kill trichomonads, but, curcumin the not toxic and can be applied in very high concentrations. Besides, curcumin would preferentially be applied topically, so that effective drug concentrations can be reached easily as topical curcumin, as a commercial solution $\left(\right.$ Curcumall $^{\circledR}$ ) as well as a gel containing $2 \%$ curcumin used successfully for trichomoniasis treatment. Kotha and Luthria (2019) in USA reported that turmeric is a curry spice that originated from India, attracted great interest in recent decades due to bioactive curcuminoids (curcum- in, demethoxycurcumin, and bisdemethoxycurcumin) it contains. They added that the curcumin, a lipophilic polyphenol may work as an anticancer, antibiotic, anti-inflammatory, and anti-aging agent as reported by several in vitro, in vivo and clinical trials.

\section{Conclusion}

The outcome results proved that curcumin $400 \mathrm{mg} / \mathrm{ml}$ in combination with tomex $90 \mathrm{mg} /$ $\mathrm{ml}$ are promising and safe anti-Trichomonas vaginalis. But, when combined with MTZ showed an active synergistic effect. Besides, Modified Diamond's medium was better than Broth medium for T. vaginalis culture.

\section{References}

Abdel Hady, NM, El-Sherbibi, GT, Morsy, TA, 2008: Treatment of Toxoplasma gondii by two Egyptian herbs. J. Egypt. Soc. Parasitol. 38, 3:1024-5.

Abouel-Nour, MF, El-Shewehy, DMM, Hamada, SF, Morsy, TA, 2016: The efficacy of three medicinal plants; garlic, ginger and mirazid and a chemical drug metronidazole against Cryptosporidium parvum: ii- Histological changes. J. Egypt. Soc. Parasitol. 46, 1:185-200

Ahmed SA, 2010: In vitro effects of aqueous extracts of garlic (Allium sativum) and onion (Allium cepa) on Trichomonas vaginalis. PUJ 3:4554.

Al-Ammash M, 2017: Study the effect of alcoholic extract of Nigella sativa seeds on Trichomomas vaginalis in vitro. IHJPAS 30:10-8.

Ali, V, Nozaki, T, 2007: Current therapeutics, their problems, and sulfur-containing-amino-acid metabolism as a novel target against infections by amitochondriate protozoan parasites. Clin. Microbiol. Rev. 20:164-87.

Allam, G, 2009: Immunomodulatory effects of curcumin treatment on murine schistosomiasis mansoni. Immunobiology 214, 8:712-27.

Alorainy, MS, 2011: Evaluation of antimicrobial activity of garlic (Allium sativum) against $E$. coli O 157:H 7. JAVS 4:149-57.

Alyasari, HF, Al-Khafaji, JKT, Al-Masoudi, HK, 2018: Inhibitory effects of garlic extract on uropathogenic Escherichia coli; Proteus mirabilis and Trichomonas vaginalis isolated from urogenital tract cases. Res. J. Pharm. Tech. 11: 1071-7.

Arbabi, M, Delavari M, Kashan, FZ, Taghizadeh M, Hooshyar H, et al, 2016: Ginger 
(Zingiber officinale) induces apoptosis in Trichomonas vaginalis in vitro. IJRM 14:691-8.

Ayrle, H, Mevissen, M, Kaske, M, Nathues, H, Gruetzner, N, 2016: Medicinal plants prophylactic and therapeutic options for gastrointestinal and respiratory diseases in calves and piglets? A systematic review. BMC Vet. Res. 12:89. Banerjee, SK, Mukherjee, PK, Maulik, SK, 2003: Garlic as an antioxidant: The good, the bad and the ugly. Phytotherapy Res 17:97-106.

Boullata, J, 2005: Natural health product interaction with medication. Nutr. Clin. Pract. 20:3351.

Buescher, R, Yang, L, 2000: Turmeric. In: Natural Food Colorants. Lauro GJ, Francis FJ, editors. New York: Marcel Dekker.

Calzada F, Yépez-mulia L, Tapia-contreras A, 2007: Effect of Mexican medicinal plant used to treat trichomoniasis. J Ethnopharmacol.113: 248-51.

Chainani-Wu N, 2003: Safety and anti-inflammatory activity of curcumin: A component of tumeric (Curcuma longa). J Altern. Complement. Med. 9, 1:161-8.

Chalamilla G, Wana J, Mhalu F, Mmari E, Majigo M, et al, 2006: Patterns of sexually transmitted infections in adolescents and youth in Dares Salaam, Tanzania. BMC Infect. Dis. 6:1-8. Changtam C, de Koning HP, Ibrahim H, et al, 2010: Curcuminoid analogs with potent activity against Trypanosoma and Leishmania species. Eur. J. Med. Chem. 45, 3:941-56.

Devasena T, Rajasekaran KN, Gunasekaran G, et al, 2003: Anticarcinogenic effect of bis-1, 7-(2-hydroxyphenyl)-hepta1,6-diene-3,5-dione a curcumin analog on DMH-induced colon cancer model. Pharmacol. Res. 47, 2:133-40.

Diamond, LS, 1957: The establishment of various trichomonads of animals and man in axenic cultures. J. Parasitol. 43:488-92.

Diamond, LS, Bartgis, IL, 1962: Axenic cultivation of Trichomonas tenax, the oral flagellate of man I. Establishment of cultures. J. Protozool. 9: 442-4.

Gelbart SM, Thomason JL, Osypowski PJ, Kellett AV, James JA, et al, 1990: Growth of Trichomonas vaginalis in commercial culture media. J. Clin. Microbiol. 28:962-4.

Hornickova, J, Kubec, R, Cejpek, K, Velíšek, J, Ovesná, J, et al, 2010: Profiles of S-alkylcysteine sulfoxides in various garlic genotypes. Czeech. J. Food Sci. 28:298-308.

Howe, K, Kissinger PJ, 2017: Single-dose co- mpared with multidose metronidazole for the treatment of trichomoniasis in women: A meta-analysis. Sex Transm. Dis. 44:30-35.

Ibrahim, AN, 2013: Comparison of in-vitro activity of metronidazole and garlic-based product $\left(\right.$ Tomex $\left.^{\circledR}\right)$ on Trichomonas vaginalis. J. Parasitol. Res. 112:2063-7.

Jennings, MR, Parks, RJ, 2020: Curcumin as an antiviral agent. Viruses 12, 11:1242.doi:10. 3390/v12111242.

Jordan WC, Drew CR, 1996: Curcumin, a natural herb with anti-HIV activity. J. Natl. Med. Assoc. 88, 6:333-7.

Khalafalla RE, Muller U, Shahiduzzaman M, et al, 2011: Effects of curcumin (diferuloylmethane) on Eimeria tenella sporozoites in vitro. Parasitol. Res. 108, 4:879-86.

Kotha, RR, Luthria, DL, 2019: Curcumin: Biological, pharmaceutical, nutraceutical, and analytical aspects. Molecules 24, 16:2930-4

Lanzotti, V, Scala, F, Bonomi, G, 2014: Compounds from Allium species with cytotoxic \& antimicrobial activity. Phytochem. Rev. 13:76981.

Mady RF, El-Hadidy W, Elachy S, 2016: Effect of Nigella sativa oil on experimental toxoplasmosis. Parasitol. Res. 115:379-390.

Martins, N, Petropoulos, S, Ferreira, ICF, 2016: Chemical composition and bioactive compounds of garlic (Allium sativum L.) as affected by pre- and post-harvest conditions: A review. Food Chem. 211:41-50.

Masamha, B, Gadzirayi, CT, Mukutirwa, I, 2010: Efficacy of Allium sativum (garlic) in controlling nematode parasites in sheep. Inter. J. Appl. Res. Vet. Med. 8:161-9.

Mimche, PN, Taramelli, D, Vivas, L, 2011: The plant-based immunomodulator curcumin as a potential candidate for the development of an adjunctive therapy for cerebral malaria. Malar. J. 10, 1:S10-6.

Monira A, 2020: Evaluation of the effect of some medicinal plants on cultured Trichomonas vaginalis. J. Infect. Dev. Ctries 14, 7: 793-9.

Muzny, CA, Schwebke, JR, 2013: The clinical spectrum of Trichomonas vaginalis infection and challenges to management. Sex Transm. Infect. 89:423-425.

Nassef, NAE, El-Melegy, MA, Beshay, EV, AlSharaky, DR, Al-Attar, TM, 2018: Trypanocidal effects of cisplatin alone and in combination with Nigella sativa oil on experimentally infect- 
ed mice with Trypanosoma evansi. Iran. J. Parasitol.13:89-99.

Patil, MJ, Nagamoti, JM, Metgud, SC, 2012: Diagnosis of Trichomonas vaginalis from vaginal specimens by wet mount microscopy, in pouch TV culture system, and PCR. JGID 4:22-5.

Paz-Bailey, G, Sternberg, M, Puren, AG, Steele, L, Lewis, A, 2010: Determinants of HIV type 1 shedding from genital ulcers in men in South Africa. Clin. Infect. Dis. 50:1060-7.

Perez-Arriaga, L, Mendoza, ML, Cortes-Zarate, R, et al, 2006: Cytotoxic effect of curcumin on Giardia lamblia trophozoites. Acta Trop. 98, 2:152-61.

Poole, DN, McClellan, RS, 2013: Global epidemiology of Trichomonas vaginalis. Sex Transm. Infect. BMJ 89:418-22.

Ross, ZM, O'Gara, EA, Hill, DJ, Sleightholme, HV, Maslin, DJ, 2001: Antimicrobial properties of garlic oil against human enteric bacteria: Evaluation of methodologies and comparisons with garlic oil sulfides and garlic powder. Appl. Environ. Microbiol. 167:475-80.

Rowley, J, Hoorn, SV, Korenromp, E, Low N, Unemo M, et al, 2019: Chlamydia, gonorrhea, trichomoniasis and syphilis: global prevalence and incidence estimates, Bull WHO 97:548-62.

Schwebke, JR, Barrientes, FJ, 2006: Prevalence of $T$. vaginalis isolates with resistance to metronidazole and tinidazole. Antimicrob. Agents Chemother. 50:4209-42.

Setzer, M, Byler, K, Ogungbe, I, Setzer, W, 2017: Natural products as new treatment options for trichomoniasis: A molecular docking investigation. Sci. Pharm. 85:5-9.

Shaaban, MT, El-Silk, SE, Tayel, MA, 2011: Efficiency of some plant extracts, carbohydrates and inorganic salts as anti-adhesion agents against the adhesion of Staphylococcus strains to HEp-2 cells. Life Sci. J. 8:1172-82.

Shahiduzzaman, M, Dyachenk, V, Khalafalla, RE, et al, 2009: Effects of curcumin on Cryptosporidium parvum in vitro. Parasitol. Res. 105, 4: 1155-61.

Sharma, RA, Gescher, AJ, Steward, W, 2005: Curcumin: The story so far. Eur. J. Canc. 41, 13: 1955-68.

Singh, TU, Kumar, D, Tandan, SK, Mishra, S K, 2009: Inhibitory effect of essential oils of Allium sativum and Piper longum on spontaneous muscular activity of liver fluke, Fasciola gigantica. Exp. Parasitol. 123:302-308.
Srivivasan, A, Menon, VP, Periaswamy, V, 2003: Protection of pancreatic beta-cell by the Srivivasan, A, Menon, VP, Periaswamy, V, 2003: Protection of pancreatic beta-cell by the potential antioxidant bisohydroxycinnamoyl methane, analogue of natural curcuminoid in experimental diabetes. J. Pharm. Sci. 6, 3:327-33.

Sutcliffe, S, Neace, C, Magnuson, NS, Reves, R, Alderete, JF, 2012: Trichomonosis, a common curable STI, and prostate carcinogenesis: A proposed molecular mechanism. PLoS Path. 8: e1002801.

Tavakkoli, A, Mahdian, V, Razavi, BM, Hosseinzadeh, J, 2017: Review on clinical trials of black seed (Nigella sativa) and its active constituent, thymoquinone. Pharmacopun. 20:179-93.

Tonkal, AMD, 2009: In vitro antitrichomonal effect of Nigella sativa aqueous extract and wheat germ agglutinin. JKAU Med. Sci. 16:17-34.

Tsevat, DG, Wiesenfeld, C, Parks, C, Peipert, JF, 2017: Sexually transmitted diseases and infertility. Am. J. Obstet. Gynecol. 216:1-9.

Wei, QY, Chen, WF, Zhou, B, 2006: Inhibition of lipid peroxidation and protein oxidation in rat liver mitochondria by curcumin and its analogues. Biochim. Biophys. Acta 1760, 1:70-7.

Yadav, VS, Mishra, KP, Singh, DP, 2005: Immunomodulatory effects of curcumin. Immunopharmacol. Immunotoxicol. 27, 3:485-97.

Sharma, P, Malla, N, Gupta, I, Ganguly, NK, Mahajan, RC, 1991: A comparison of wet mount, culture and enzyme linked immunosorbent assay for the diagnosis of trichomoniasis in women. Trop. Geogr. Med. 43:257-60

Walsh, PS, Metzger, DA, Higuchi, R, 1991: Chelex 100 as a medium for simple extraction of DNA for PCR-based typing from forensic material. Bio-Tech. 10:506-13.

Unemo, M, Bradshaw, CS, Hocking, JS, de Vries, HJC, Francis, SC, et al, 2017: Sexually transmitted infections: challenges ahead. Lancet Infect. Dis. 17, 8:e235-79.

Mallo, N, Lamas, J, Sueiro, R, Leiro, J, 2020: Molecular targets implicated in the antiparasitic and anti-inflammatory activity of the phytochemical curcumin in trichomoniasis. Molecules 25, 22:5321.

Wachter, B, Syrowatka, M, Obwaller, A, Walochnik, J, 2014: In vitro efficacy of curcumin on Trichomonas vaginalis. Wien Klin. Wochenschr. 126, 1:S32-6. 